ASEE 2001 : International Division Paper (submitted)

\title{
A Summer Immersion in French Engineering and Language
}

\section{April Wilson and David Ollis, Chemical Engineering Department,NCSU, Raleigh, NC 27695-7905}

A major French engineering school, the Ecole Superieure de Chimie Physique Electronique de Lyon, or CPE-Lyon, decided to fund a seed initiative aimed at increasing the number of American engineering students who are ready, willing, and able to spend a substantial academic experience abroad. In June 2000, CPE created and carried out a three-week immersion program in France involving American engineering students, titled "Summer School for Science and Engineering Students". Their expectation was that such an education immersion program, experienced early in the undergraduate engineering career, could create a pool of American students who would have an interest in and ability to return for a later academic semester or year abroad at CPE-Lyon.

\section{CPE-PROGRAM}

The summer school program organized by CPE appears in Table 1. The activities for the intensive three week "immersion" in French language and technical instruction included 45 hours of French language, 45 hours of science courses and/or workshops, and 2 industrial visits. The program was organized to accommodate student interests corresponding to the strengths of CPE-Lyon: chemistry, chemical engineering, and electrical engineering/computer science.

Financing of the program was covered in the following manner: CPE-Lyon provided free instruction and student dorm rooms for the entire three week period. NSF/SUCCEED funds provided for air ticket purchase for all six participating students from NCSU engineering; a seventh (non-engineering) NCSU student was also provided with CPE support, and paid his or her own way

\section{Organization: Student recruiting and selection}

Information about the trial program was relayed via mass e-mail to students in the NCSU University Scholars Program, which recognizes high-achieving, well-rounded students. This e-mail included a description of the proposed summer school and a brief interest survey, which asked students about their academic background and French experience.

About 30 student responses were received for the 4 positions originally announced, attesting to the high level of student interest in a summer abroad program. More spaces became available for NC State students when the other two invited universities were not organized in time to recruit students in this first program year. Ultimately, a total of seven State students of various majors, year of study, and French backgrounds were selected to participate in the summer program. 


\section{TABLE 1}

\section{SUMMER SCHOOL AT CPE LYON}

FIRST WEEK, Monday 5 June - Friday 9 June, 2000

16 hours of French courses

6 hours of scientific lectures

4 hours of scientific workshop

1 Industrial visit

SECOND WEEK, Monday 12 June - Friday 16 June, 2000

16 hours of French courses

9 hours of scientific lectures

7 hours of scientific workshop

THIRD WEEK, Monday 19 June - Friday 23 June, 2000

13 hours of French courses

6 hours of scientific courses

5 hours of scientific workshop

3 hours of poster/oral preparation

4 hours of poster/oral presentation

1 Industrial visit

TOTAL

45 Hours French

45 Hours of scientific courses or workshops

2 Industrial visits

Scientific courses:

3 hrs each of: chemical engineering, polymers, image processing, history of science, future engineering, physics, and quantum mechanics.

Students also worked on individual projects with a French grad student and professor This work was presented orally and in poster form at the end of the Summer School.

The initial four participants were chosen based upon years of prior study of the French language, undergraduate grade point average at NCSU, and enrollment in one of the engineering majors preferred by CPE-Lyon: chemical, electrical /computer science, or industrial. Two additional students were added as CPE invited a larger NCSU group. The chosen students and their majors and preparatory backgrounds are summarized below. These included three chemical engineers, two electrical engineers, and a textile 
chemistry major. A graduating NCSU chemical engineer with a previous summer experience in Lille, France accompanied the group to serve as rapporteur.

\section{TABLE 2}

\section{NCSU STUDENT CPE-LYON PARTICIPANTS}

\begin{tabular}{|c|c|c|}
\hline Name & Major & Year \\
\hline Bale, Arathi & $\mathrm{EE}$ & sophomore \\
\hline Huang, William & $\mathrm{EE}$ & junior \\
\hline Mead, Benjamin & Textiles & sophomore \\
\hline Moss, Rebecca(Jody) & $\mathrm{ChE}$ & freshman \\
\hline Summers, David & EE/French & sophomore \\
\hline Williams, Brooke & ChE/French & junior \\
\hline
\end{tabular}

Wilson, April ChE senior(rapporteur)

yrs French

(middle, high, NCSU)

6
2
5
7
7
5

4

During spring 2000 semester, the students met with the organizing professor to make travel arrangements and receive information about the program from CPE. The students also briefly met with representatives from the French school when the latter representatives were in the US.

That this program was organized by a professor rather than the campus Study Abroad Office was unique, and might partially explain why there was a higher interest level at NCSU than at the other two schools that were invited to participate. At the schools that did not send students, the professors in contact with CPE-Lyon did not actively recruit students--the recruitment was done by their respective study abroad offices. It seems that having a technical professor recruit summer school participants may be an effective recruiting method in future years. Since technical students are not typically aimed towards studying abroad (or to their study abroad offices), these students need to be directly informed about student exchange programs such as this summer school. In addition, having an organizing professor who is familiar with the foreign school can help the students mentally prepare for their study abroad experience.

In that vein, the NC State students were further fortunate to have met the French CPE program organizers in the States before leaving for France. In March, 2000, these representatives from France were visiting their own CPE students who were studying at NC State and UNC-Chapel Hill, and a meeting with the NCSU summer students was arranged. This visit helped alleviate the Americans' concerns about the summer by 
giving them some familiar faces to look for upon their arrival. The visit also allowed the CPE representatives to ascertain the academic needs of the students and adjust the program accordingly.

During spring 2000, the NCSU students were proactive in organizing themselves for the trip. A participant e-mail list-serve proved useful for this purpose, allowing students and professor to easily organize meetings, French practice sessions, and travel plans. The students went together to French restaurants in Raleigh to practice speaking the language and to get to know each other before the trip. These social events helped the students become more comfortable with each other before they arrived in Europe, which probably eased in their cultural transition. Since the students had already met in social settings, they did not feel they were travelling with strangers, and could focus on adjusting to the foreign culture.

The students also organized themselves to allow for a prior week in Spain (four students), and follow-on visits to Italy (four students) and Paris (two students). The chance to travel together before the intensive academic program in Lyon further developed student rapport within the group in a way favorable to the program outcome.

\section{Student Housing}

On arrival in Lyon, the students were housed in a student residence on the outskirts of Lyon, where the cost of lodging was provided by CPE-Lyon. The lodgings were comfortable, and each student had a private room with a shower. The students used public transportation to travel to the school. The residence was distant from the downtown area and from the school, a circumstance which somewhat diminished conversations with French engineering students.

\section{Interaction with Peers}

The American students first met with their French peers when they all went on an annual end-of-year retreat held on the Mediterranean coast of France. Despite unusually cool weather, the chance to spend a social weekend together (sports, music, food and conversation) with their French student counterparts proved successful.

The Lyon cultural opportunities sought out by the students themselves were also important in making the trip fulfilling. Example outings involving all or several of the NCSU students were: museums (of tapistries, of silk, of dolls, etc), a spectacular floral park and zoo, French movies and an opera, and a performance of the play "Julius Caesar" in Lyon's Roman theater.

A lovely gastronomic farewell dinner hosted by CPE-Lyon and held in the old quarters of Lyon concluded this fine cultural menu.

\section{Classes/Projects}




\section{a. Technical classes}

In the technical classes, the students were introduced to polymer chemistry, quantum mechanics, and image processing. The students also attended lectures about the history of science and the future of engineering. In addition, the students worked with graduate students and professors at $\mathrm{CPE}$ to research a topic in their undergraduate fields of study. This research project culminated in a 10-minute poster presentation on the last day of the program.

The biggest challenge to NCSU students was acclimating to the French academic schedule: classes 9-5 daily, mostly in French, with one 15 minute break am and pm. This pace in "language immersion" left the students tired in the evenings. While bus service to downtown Lyon was good, the distance of dorms from center city limited weekday evening social life and cultural possibilities. The largest benefit of the courses, as intended by CPE, was undoubtedly hearing technical French spoken in several subjects, and by several different speakers.

\section{b. French classes}

French classes were also an integral part of the daily curriculum. The French instructor tested all members on day one, discerned two levels of competence, and managed to provide conversation and pronunciation for the more advanced, while giving vocabulary and grammar as well to the less experienced. An invitation for an afternoon at the instructor's house also provided language and refreshments in a more casual setting. The students were uniformly appreciative of the instructor's dedication and engagement with them during this intensive language exercise.

\section{Informal evaluation}

In this first offering of a novel "seed" experiment in international exchange, both CPE-Lyon and NCSU were experimenting with the proposed notion of an early summer technical immersion in French. No formal evaluation was carried out. We report informal comments by both the CPE faculty and the NCSU students

\section{CPE faculty feedback}

Interviews with the professors who taught the summer school revealed that they were very willing and interested in participating in the program. They said that it did not take much time to prepare the lessons, as they were teaching an elementary level of familiar subjects, and indicated that they would probably participate if the program duration was extended to, e.g., six weeks.

The project work varied in its scope and the level of guidance each student received from their advisor. Some students worked in their advisor's labs and attended research group meetings. Others had work that was more independent, and required them to simply gather information about their topic in the library. The advisors also were 
eager to participate in the program, although the students' projects did not advance the advisors' work. These faculty suggested that the students could have benefited from having more time to research their topic area and prepare their presentation.

A sentiment expressed by the French professors and project advisors was that they desired to have received information earlier about the students' academic backgrounds. The selection of the NCSU students was completed only about two months before the commencement of the program; future programs will feature an earlier selection process.

To help the CPE organizers plan the program for next year, they should be provided copies of the students' transcripts and resumes with course descriptions well in advance of the program commencement. With this information, the classes and projects could be better tailored to the students' level of study, as these were sometimes too advanced for the Americans. Also, NCSU student selection should be finalized earlier; perhaps the timeline for this program could follow that for our other university study abroad summer programs, which have an application deadline in February.

\section{NCSU Student comments}

The NCSU students found the lectures interesting and diverse, and the French professors to be very patient with the student language difficulties. It was challenging for the students to adjust to the French style of teaching, in which class lectures last several hours each. It was novel, and often fatiguing, for them to listen to the foreign language for such long periods of time.

More advance preparation stateside should help with this "language endurance" problem. First, it would be useful for the summer exchange students to attend some technical French lectures before starting the program in France. Several students participating in this first summer school had not taken a French class since high school (four years ago for one participant). If the students could have heard more spoken French before leaving the US, their ears could have been better acclimated to hearing the language, and it would have been easier for them to listen longer. Perhaps the students could attend brief lectures given by a French professor at the American university or by a technical professor who speaks French. This would help students who have not recently studied French to begin to recall the language, and help all the students get acclimated to hearing the foreign language A four week duration, rather than three, is envisaged by CPE for summer 2001, thus allowing for more informal exploration and conversation.

It may be beneficial for the students to receive academic credit during their summer study at CPE. Receiving summer school credit would be a good enticement to get students to participate because many engineering students already take some summer school classes. If the program cost to the student is increased, the students will be more likely to pay for a program from which they will receive course credit. Also, if program advertising is accomplished with academic advising, the advisors would probably be more likely to mention the program if their students will receive credit If the students are to receive technical credit, it might be necessary to separate the students by major and 
teach classes that are relevant to their respective majors. Alternately, for a language credit, such separation would not be necessary.

\section{DID THE CPE-LYON PROGRAM ACHIEVE ITS GOALS?}

That seven NCSU students were recruited, went to France, were impressed by and, in turn, impressed the French faculty with their talents and determination, and had an experience both demanding and enjoyable is clearly demonstrated.

However, the purpose of the CPE-Lyon program was to recruit additional American students for enhancement of US-CPE-France exchanges. Is such likely to occur? We summarize individual student responses and pre-dispositions:

All students were interested in France, and are interested under appropriate circumstances.

Brooke Williams is returning to France for a year at the Sorbonne. Her courses will be largely or completely non-technical

David Summers continues to plan for a spring 2001 semester in France, as before, at a technical or non-technical school.

Jody Moss wishes to return to CPE next summer, in the role of rapporteur for the summer 2001 experience.

Ben Mead would be interested in a summer internship in France or in Canada.

William Huang and Arathi Bale are also interested in further overseas experiences, perhaps in France.

April Wilson (rapporteur and co-author) has a heightened interest in an eventual international career with a French connection.

These data indicate that the CPE summer experience can be profitably pursued by NCSU students at any class level (freshman, sophomore, junior However, to more firmly aid CPE in developing a reliable exchange program with NCSU, a future NCSU effort should concentrate on recruiting students with a planned expectation of attending CPE in a later semester: Information about the program could be given to students when they meet with their academic advisors, and would be received by a more general and larger student population.

This goal could be accomplished, potentially, through the following route. For each participating NCSU discipline (chemistry, electrical/computer engineering and chemical engineering):

(1) Develop an example junior year semester scenario involving CPE courses and NCSU equivalencies, and 
(2) Develop in ECE/CE and in Chemistry a NCSU faculty colleague who will assist, with D. Ollis (chemical engineering) in recruiting and advising potential CPE students, and in grading returning CPE participants on an NCSU appropriate scale. Professor Stefan Franzen, who currently advises a CPE student in the NCSU chemistry $\mathrm{PhD}$ progam, is an example candidate.

Additionally, we should work more directly with the NCSU Study Abroad program, the University Scholars program, and academic advising to fit this potential CPE-France program under the larger, better endowed and staffed NCSU programs for study abroad for academic credits.

\section{PROPOSED ACTION PLAN FOR YEAR 2000-2001}

Assuming CPE concurrence and CPE on-site support of the same kind as last June, we propose the following:

1. Recruit new CPE-Lyon program students in Fall 2000

2. Seek students at end of freshman and sophomore years

3. Provide 1 hour/week technical French lectures in spring 2001

4. Encourage student listserv to deepen lingual and social development of student group

5. $\quad$ Send CPE student transcripts/profiles in early spring

6. Create a stronger expectation of a follow-up semester in CPE-Lyon.

\section{CONCLUSIONS}

A summer school program such as the one tested this summer at CPE-Lyon appears be an effective method for attracting technical students to study abroad programs. The engineering participants from NC State had very positive experiences, and several of the students have discussed returning to CPE for a lengthier study abroad experience. It was helpful for the American students to realize that the curriculum at CPE is similar to engineering curricula at American universities, and that studying there would not hinder their progress towards their technical degrees. Further, experiencing the language transition enabled the students to understand what to expect if they were to study abroad in France. The Americans found that their language difficulties were minor, and decreased as they became more immersed in the language. The one student who had only taken two years of French in high school four years ago nonetheless was able to carry on a simple conversation completely in French by the end of the program.

Currently, the CPE-Lyon program is targeted for American students in their firstor second- year of study. This does seem to be an appropriate group for this program, as these are the students who will have time to plan a study abroad experience for their junior or senior year.

We note that the first and second years of engineering study in America do not correspond to the first and second years of engineering study at CPE. The American 
students are actually at a earlier academic level than French students would be in their first or second year at CPE. The latter corresponds closely to the American junior and senior years. This circumstance is possibly part of the reason some of the lectures and projects were a bit advanced for the American students. Providing CPE with participants' transcripts and course descriptions during the planning stages of the program would alleviate this problem.

\section{SUMMARY}

This summer school program could be a strong opportunity for first- or secondyear technical students who are considering study abroad. In the future, students should be recruited to the program by academic advisors or technical professors. Also, it will be important for the program logistics to be finalized sooner, and for the organizers in France to be provided earlier with more information about the American participants. Consideration might be given to increasing the length of the summer program in some fashion to give the students a fuller experience. Although less travel funding will be available in future years, with adequate advance planning and the awarding of course credit, the American participants may be willing to absorb the additional costs

\section{Acknowledgements}

We thank NSF/SUCCEED for the financial support (air transportation for NCSU students) for this NCSU-French engineering experiment, and Dr. Alex Miller, Director of University Scholars Program, and Associate to Vice Chancellor for the Arts Program NCSU, for his assistance in recruiting student participants.

END 